\title{
Finite-Element Model-Based Design Synthesis of Axial Flux PMBLDC Motors
}

\author{
Fasil, Muhammed; Mijatovic, Nenad; Jensen, Bogi Bech; Holbøll, Joachim
}

Published in:

IEEE Transactions on Applied Superconductivity

Link to article, DOI:

10.1109/TASC.2016.2537743

Publication date:

2016

Document Version

Peer reviewed version

Link back to DTU Orbit

Citation (APA):

Fasil, M., Mijatovic, N., Jensen, B. B., \& Holbøll, J. (2016). Finite-Element Model-Based Design Synthesis of Axial Flux PMBLDC Motors. IEEE Transactions on Applied Superconductivity, 26(4), [0602905].

https://doi.org/10.1109/TASC.2016.2537743

\section{General rights}

Copyright and moral rights for the publications made accessible in the public portal are retained by the authors and/or other copyright owners and it is a condition of accessing publications that users recognise and abide by the legal requirements associated with these rights.

- Users may download and print one copy of any publication from the public portal for the purpose of private study or research.

- You may not further distribute the material or use it for any profit-making activity or commercial gain

- You may freely distribute the URL identifying the publication in the public portal 
This article has been accepted for publication in a future issue of this journal, but has not been fully edited. Content may change prior to final publication. Citation information: DOI 10.1109/TASC.2016.2537743, IEEE Transactions on Applied Superconductivity

MT24-3POBI-13.R1 


\title{
Finite Element Model Based Design Synthesis of Axial Flux PMBLDC Motors
}

\author{
M. Fasil, N. Mijatovic, B. B. Jensen and J. Holboll
}

\begin{abstract}
This paper discusses design synthesis of a permanent magnet brushless DC (PMBLDC) machine using a finite element (FE) model. This work differentiates itself from the past studies by following a synthesis approach, in which many designs that satisfy performance criteria are considered instead of a unique solution. The designer can later select a design, based on comparing parameters of the designs, which are critical to the application that the motor will be used. The presented approach makes it easier to define constraints for a design synthesis problem. A detailed description of the setting up of a FE based design synthesis problem, starting from the definition of design variables, FE model of the machine, how the design synthesis is carried out, and to, how a design is finalised from a set of designs that satisfy performance criteria, is included in this paper. The proposed synthesis program is demonstrated by designing a segmented axial torus PMBLDC motor for an electric two-wheeler.
\end{abstract}

Index Terms-Axial flux machines, PMBLDC motor, finite element model, electrical machine design synthesis, segmented stator tooth, integer constrained genetic algorithm.

\section{INTRODUCTION}

Permanent magnet (PM) brushless machines offer higher efficiency and power density compared to machines that require externally supplied field current [1]. Radial flux (RF) and axial flux (AF) are the two major configurations of PM rotating machines. AF machines offer higher torque density compared to RF motors for low-speed application such as an in-wheel motor for electric two-wheelers, where the axial length of the machine is restricted by the limited space available [2], [3]. Many approaches exist to synthesize an optimized design of AF machines [4]-[9].

This work implements an FE based design synthesis approach by developing a design program for a segmented axial torus (SAT) permanent magnet brushless DC (PMBLDC) machine. The SAT motor topology [10]-[13] is a variation of SSDR-NS (single stator dual rotor north-south) axial flux motor topology [14] and has no stator yoke. Exploded view of the SAT PMBLDC hub motor is shown in Fig. 1. A SAT PMBLDC motor with a voltage rating of $48 \mathrm{~V}$ and produces

This work was supported by EU-FP7 NANOPYME Project (No. 310516). (Corresponding author: M. Fasil)

M. Fasil is with Department of Electrical Engineering, Technical University of Denmark, Kgs. Lyngby, 2800, Denmark (e-mail: mfasil@elektro.dtu.dk).

N. Mijatovic is with Department of Electrical Engineering, Technical University of Denmark, Kgs. Lyngby, 2800, Denmark (e-mail: nm@elektro.dtu.dk).

B. B. Jensen is with Department of Science and Technology, University of the Faroe Islands, Torshavn, FO-100, Faroe Islands (email: bogibj@ setur.fo)

J. Holboll is with Department of Electrical Engineering, Technical University of Denmark, Kgs. Lyngby, 2800, Denmark (e-mail: jh@elektro.dtu.dk).

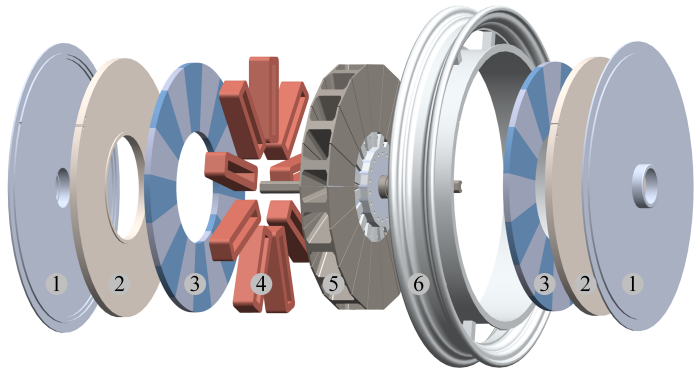

Fig. 1: Exploded view of SAT PMBLDC motor (1. end cover, 2. rotor yoke, 3. magnets, 4. stator winding, 5. stator and 6. wheel rim).

$20 \mathrm{Nm}$ at $340 \mathrm{rpm}$ is designed to demonstrate the design program.

\section{Finite ELEMENT MODEL BASED DESIGN SYNTHESIS}

The design synthesis program presented here has two parts. The first part is an FE based design tool that will estimate the motor dimensions based on a given specification and constraints. The second part is a search program that will use the design tool to identify designs satisfying the performance criteria specified by the designer. This section will explain design variables of SAT PMBLDC motor, FE based design tool, and search program.

\section{A. Design variables of SAT PMBLDC motor}

The set of dimensions that define the geometry of the SAT PMBLDC motor, excluding the winding is shown in Fig. 2. The dimensions as seen from the inner periphery of the motor are indicated in Fig. 2(b). The design variables of SAT

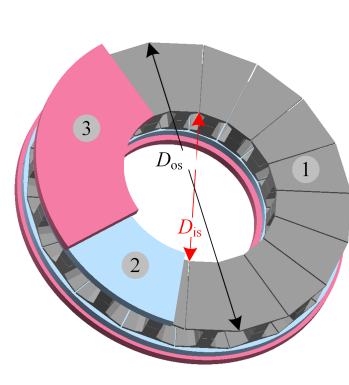

(a)

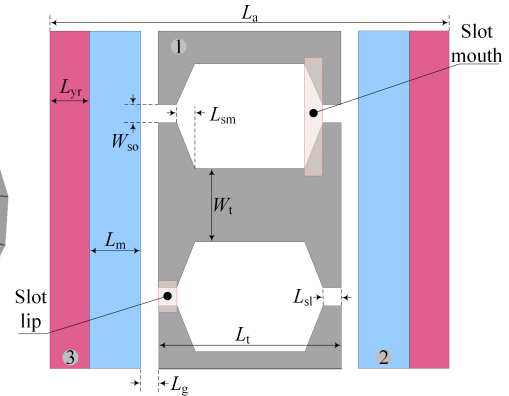

(b)
Fig. 2: Variables that define the geometry of the SAT PMBLDC motor (1. segmented stator, 2. magnets, and 3. rotor). (a) Cutaway model. (b) Sectional view of inner periphery. The definition of variables are given in appendix $\mathrm{A}$. 
PMBLDC motor can be grouped into three sets: specification, primary, and secondary variables as listed in Table I. The primary variables are those design parameters that can be changed independently, without affecting the value of other primary variables. For example, the length of airgap can be changed alone to generate different designs. The secondary variables are calculated by the design tool for given values of specification and primary variables. It is important to note that some variables can be either primary or secondary. For example, if the axial length of the machine is a design constraint, then the outer diameter of the stator can be a secondary variable.

TABLE I

DESIGN VARIABLES OF SAT PMBLDC MOTOR

\begin{tabular}{lll}
\hline \hline Specification & Primary & Secondary \\
\hline Rated voltage & Number of stator slots & Width of stator tooth \\
Rated power & Number of rotor poles & Depth of rotor yoke \\
Rated speed & Length of airgap & Diameter of a coil turn \\
& Outer diameter of stator & Number of turns/coil \\
& Gross slot fill factor & Axial length of tooth \\
& Width of slot opening & Axial length of motor \\
& Depth of slot lip & \\
& Depth of slot mouth & \\
& Depth of magnet & \\
& Magnet overhang & \\
& Diameter ratio of stator & \\
& Max. current density & \\
& Ratio of pole arc to pole pitch & \\
& Max. rotor yoke flux density & \\
& Max. stator tooth flux density & \\
\hline \hline
\end{tabular}

\section{B. Finite element model based design tool}

When developing a design program for newer machine topologies, the use of FE models helps to avoid the time required for development of lumped parameter or analytical models. Though, the FE model provides accurate solutions, it requires longer time for solving each design iteration compared to the other two models. The design tool is shown in Fig. 3 in the form of a flowchart, which will give an overview of different stages involved in the calculation of secondary variables and the motor performance.

In the first stage, the rotor yoke depth is calculated iteratively using a stator-less three-dimensional (3D) static FE model of a SAT PMBLDC motor. Iteration starts with a minimum rotor yoke depth, and the depth will be increased in each iteration. Iterations stop when the maximum flux density inside the rotor yoke is below the value of flux density constraint. Similarly, the program calculates stator tooth width by gradually increasing tooth width of the FE model from a minimum value. Iteration stops when the maximum tooth flux density is below the value set by the constraint. During this stage, the axial length of the tooth is set as twice the depth of slot lip and mouth together. The program records average airgap flux density at the end of this stage, $B_{\mathrm{g} 0}$ for future calculations. The EMF generated in the phase winding
FE Iteration

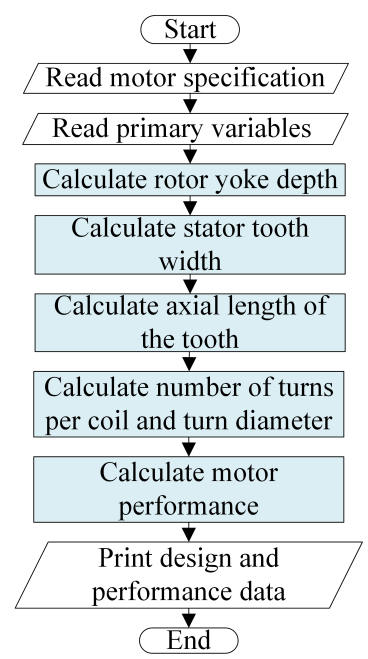

Fig. 3: Flowchart of design tool showing different stages in the estimation of secondary variables and the motor performance.

of a PMBLDC motor because of the rotor movement can be expressed as [15]

$$
\begin{aligned}
E_{\mathrm{ph}} & =P \phi Z \frac{N_{\mathrm{r}}}{60} \\
& =B_{\mathrm{g}} \frac{\pi}{4}\left(D_{\mathrm{os}}^{2}-D_{\mathrm{is}}^{2}\right) \frac{2 N_{\mathrm{c}} N_{\mathrm{s}}}{2 \times 3} \frac{N_{\mathrm{r}}}{60} \\
& =\frac{N_{\mathrm{r}}}{60} \frac{N_{\mathrm{s}}}{3} \frac{\pi}{4}\left(D_{\mathrm{os}}^{2}-D_{\mathrm{is}}^{2}\right) B_{\mathrm{g}} N_{\mathrm{c}}
\end{aligned}
$$

where, $P$ is the number of rotor poles, $\phi$ is the flux per pole, $Z$ is the number of conductors in series per phase, $N_{\mathrm{r}}$ is the rated speed of machine, $B_{\mathrm{g}}$ is the average airgap flux density, $N_{\mathrm{c}}$ is the number of turns per coil, $N_{\mathrm{S}}$ is the number of stator slots. The rated output power of a three-phase PMBLDC motor is given by

$$
\begin{aligned}
P_{r} & =2 E_{\mathrm{ph}} I_{\mathrm{ph}} \\
& =2\left[\frac{N_{\mathrm{r}}}{60} \frac{N_{\mathrm{s}}}{3} \frac{\pi}{4}\left(D_{\mathrm{os}}^{2}-D_{\mathrm{is}}^{2}\right) B_{\mathrm{g}} N_{\mathrm{c}}\right]\left(\frac{\pi}{4} D_{\mathrm{ct}}^{2} J\right) \\
& =\left[\frac{N_{\mathrm{s}}}{3 \times 4} B_{\mathrm{g}} J\left(D_{\mathrm{os}}^{2}-D_{\mathrm{is}}^{2}\right) \frac{2 \pi N_{\mathrm{r}}}{60}\right]\left(N_{\mathrm{c}} \frac{\pi}{4} D_{\mathrm{ct}}^{2}\right) \\
& =\left[\frac{N_{\mathrm{s}}}{12} J B_{\mathrm{g}}\left(D_{\mathrm{os}}^{2}-D_{\mathrm{is}}^{2}\right) \omega_{\mathrm{r}}\right]\left(K_{\mathrm{sff}} \times \text { Slot area }\right)
\end{aligned}
$$

where, $D_{\text {ct }}$ is the diameter of a coil turn, $J$ is the current density of a coil turn, and $K_{\text {sff }}$ is the gross slot fill factor. Therefore, the slot area can be calculated as from (2) as

$$
\text { Slot area }=\frac{12 T_{\mathrm{r}}}{K_{\mathrm{sff}} N_{\mathrm{s}} J B_{\mathrm{g}}\left(D_{\mathrm{os}}^{2}-D_{\mathrm{is}}^{2}\right)}
$$

where, $T_{\mathrm{r}}$, is the rated torque of the machine. The axial length of the tooth can be calculated from the area of stator slot (refer Fig. 2(b)), and the flowchart of Fig. 4 shows iterative steps implemented to calculate the axial length of the tooth. In the next stage, the design tool will calculate the number of turns per coil and the diameter of a turn iteratively using back EMF equation (1) as shown in the flowchart of Fig. 5. The design generation concludes by calculating the motor performance data such as input current, efficiency, losses, etc. 


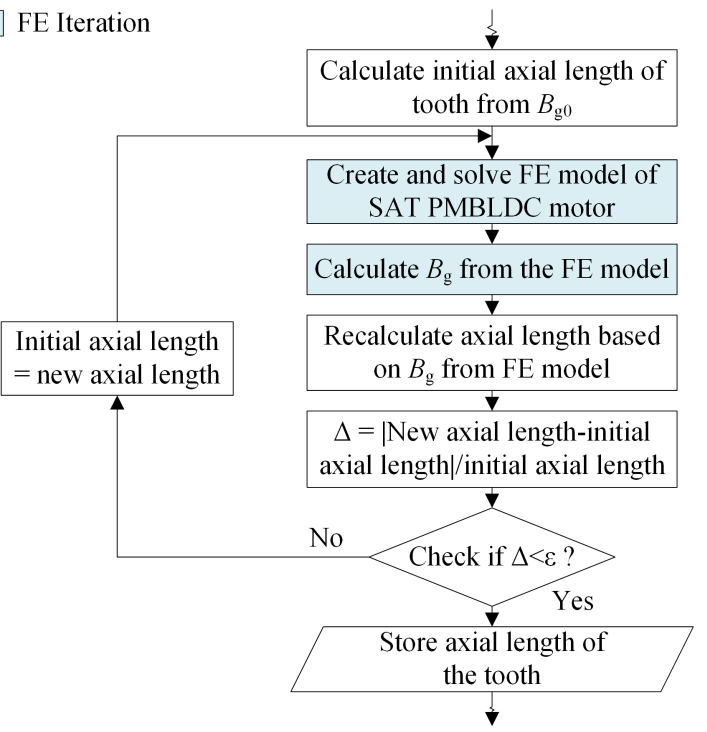

Fig. 4: Flowchart for calculating the axial length of stator tooth iteratively using the FE model of SAT PMBLDC motor. $\varepsilon$ is the tolerance for convergence.

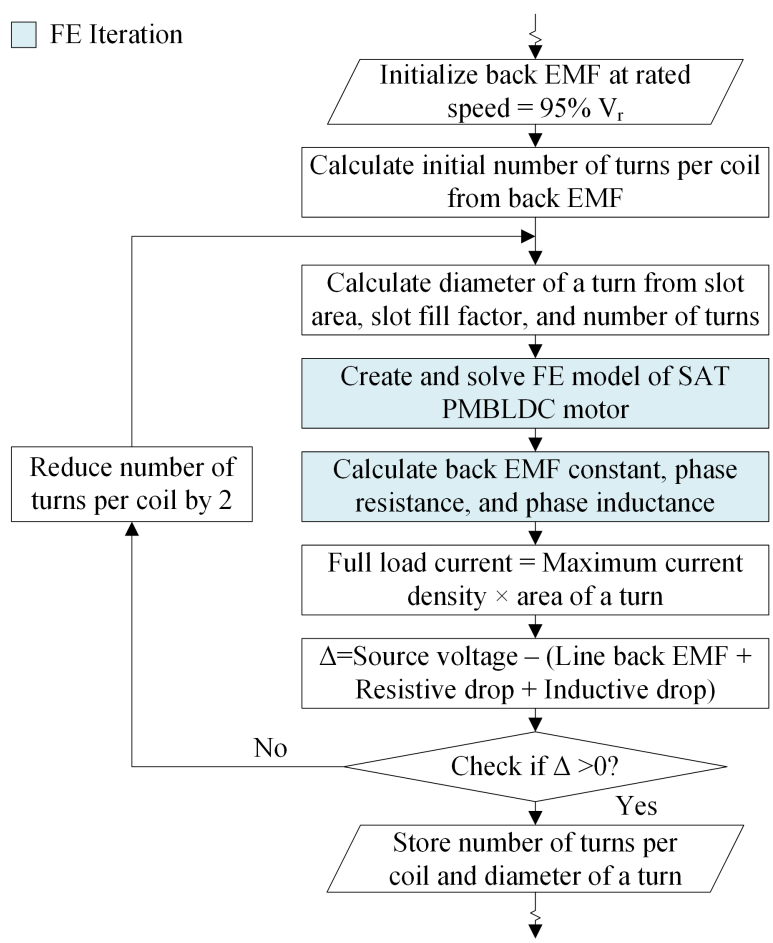

Fig. 5: Flowchart for calculating the number of turns of the coil and the diameter of a turn iteratively using the FE model of SAT PMBLDC motor.

using the FE model of the developed design. The design tool is implemented using Excel-VBA ${ }^{\mathrm{TM}}$ and commercial FE software package, MagNet ${ }^{\mathrm{TM}}$.

\section{Search program}

The search program finds designs that meet performance targets set by the designer. The objective function of the search program uses the design tool described in section II-B, and the search program is implemented using integer constrained genetic algorithm available in MATLAB ${ }^{\mathrm{TM}}$. The integer constrained algorithm helps to define discrete realistic set of values for primary variables. All intermediate points of the optimisation process are recorded, and the search program is stopped when there is no major improvement in the value of the objective function.

\section{DESIGN SYNTHESIS OF SAT PMBLDC MOTOR FOR ELECTRIC TWO-WHEELER POWERTRAIN}

A SAT PMBLDC in-wheel motor for a battery operated two-wheeler has been designed using the FE based synthesis program. The specification of the powertrain, shown in Table II, has been identified using the methodology described by Ehsani et al. [16].

TABLE II

SPECIFICATION OF SAT PMBLDC MOTOR POWERTRAIN FOR THE ELECTRIC TWO-WHEELER

\begin{tabular}{ll}
\hline \hline Parameter & Value \\
\hline Maximum mass of vehicle including load & $130 \mathrm{~kg}$ \\
Maximum speed of vehicle & $30 \mathrm{~km} \mathrm{~h}^{-1}$ \\
Time to reach maximum speed & $20 \mathrm{~s}$ \\
Rated speed of motor & $340 \mathrm{rpm}$ \\
Rated torque of motor & $20 \mathrm{~N} \mathrm{~m}$ \\
Rated voltage of battery & $48 \mathrm{~V}$ \\
\hline \hline
\end{tabular}

The number of primary variables that require optimisation has been reduced considerably by following the design guidelines of PMBLDC motor [17] and values of these variables are listed in Table III. The airgap length is decided based on

TABLE III

PRIMARY VARIABLES OF SAT PMBLDC MOTOR, EXCLUDING OPTIMISATION VARIABLES, AND THEIR VALUES

\begin{tabular}{ll}
\hline \hline Variable name & Value \\
\hline Number of slots-poles & $18-16$ \\
Length of airgap & $0.4 \mathrm{~mm}$ \\
Outer diameter of stator & $260 \mathrm{~mm}$ \\
Gross slot fill factor & $50 \%$ \\
Width of slot opening & $1 \mathrm{~mm}$ \\
Depth of slot lip & $2 \mathrm{~mm}$ \\
Depth of slot mouth & $2 \mathrm{~mm}$ \\
Current density of coil & $4.5 \mathrm{~A} \mathrm{~mm}{ }^{-2}$ \\
Ratio of pole arc to pole pitch & 1 \\
Max. flux density of rotor yoke & $1.2 \mathrm{~T}$ \\
Max. flux density of stator tooth & $1.6 \mathrm{~T}$ \\
\hline \hline
\end{tabular}

the manufacturing tolerances. The maximum possible outer diameter of the motor for a 14 inch wheel is selected to limit the axial length. The SAT topology allows a higher fill factor than the 30 to $40 \%$ used in classical machines. The sections around the slot opening are made sufficiently thick based on FE studies of the motor to avoid the saturation in these areas. As the motor is not force-cooled, a current density of less than $5 \mathrm{~A} \mathrm{~mm}^{-2}$ is selected. The machine will be using bonded rare earth magnets with a remanence of $0.58 \mathrm{~T}$ and a coercivity of $330 \mathrm{kA} \mathrm{m}^{-1}$. The ease of assembly of magnets was given higher priority than the cost saving via magnet material reduction, hence a pole arc to pole pitch ratio of one is selected. Solid soft-iron is used to make the 
rotor yoke; therefore, the maximum flux density is set to $1.2 \mathrm{~T}$ to reduce the core loss. The cold rolled silicon steel lamination of grade M-36 is used to make the stator tooth, and a maximum flux density $1.6 \mathrm{~T}$ is achievable in this material without considerable core loss.

The three remaining primary variables: depth of the magnet $\left(L_{\mathrm{m}}\right)$, ratio of magnet overhang to radial length of the stator $(h)$, and diameter ratio of the stator $\left(\lambda_{\mathrm{d}}\right)$ are optimised to generate SAT PMBLDC motor designs. The discrete set of values for these parameters are shown in Table IV. The SAT

TABLE IV

PRIMARY VARIABLES USED AS OPTIMISATION VARIABLES IN DESIGN SYNTHESIS OF SAT PMBLDC MOTOR AND THEIR RANGE

\begin{tabular}{ll}
\hline \hline Variable name & Range \\
\hline Depth of magnet & $7 \mathrm{~mm}$ to $10 \mathrm{~mm}$ in steps of $0.5 \mathrm{~mm}$ \\
Magnet overhang & $0 \%, 5 \%, 10 \%$ \\
Diameter ratio of stator & $45 \%$ to $60 \%$ in steps of $2.5 \%$ \\
\hline \hline
\end{tabular}

PMBLDC motor topology has a lower core loss compared to topologies with stator yoke [18]. In addition, the low flux density threshold selected for the rotor yoke and the stator tooth will help to reduce core losses generated in them. Therefore, the synthesis program is devised to identify the designs with low conduction losses $\left(P_{\mathrm{cu}}\right)$, with the assumption that the core loss variation among these designs will be negligible.

The 3D FE model of SAT PMBLDC motor utilizing the geometrical symmetry, excluding the elements of air volume, used in the design synthesis of the in-wheel motor is shown Fig. 6. Only one coil belong to each phase is modelled and

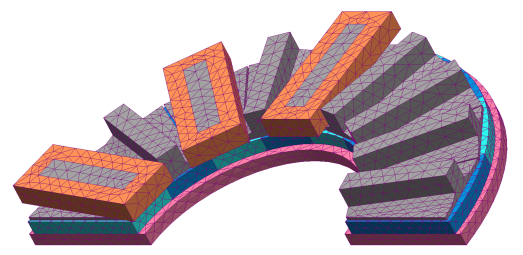

Fig. 6: The FE model of SAT PMBLDC motor used in the design synthesis of in-wheel motor.

the phase back EMF is calculated with the help of winding factor presented by Ishak et al. [19]. The synthesis took 73.6 hours and generated 551 designs. The result of genetic algorithm optimisation is shown in Fig. 7. The design synthesis is stopped at tenth generation because there was no significant change in minimum loss from the fourth generation onwards. Moreover, the average loss is moving towards the minimum loss shows the convergence.

The minimum loss designs from the design synthesis that satisfy geometrical constraints are listed in Table V. The SAT PMBLDC motor is designed for battery operated two-wheeler, and a motor with a lower current $(I)$ at rated load will improve the range of the vehicle. Therefore, design \#410 is selected because it is the one with the lowest rated current.

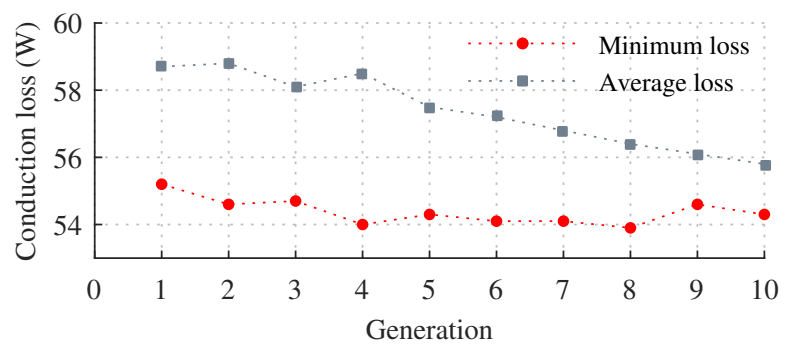

Fig. 7: The results of FE based design synthesis of SAT PMBLDC in-wheel motor using genetic algorithm.

TABLE V

Minimum Loss Designs FRom The Design Synthesis of SAT PMBLDC IN-WHEEL MOTOR

\begin{tabular}{llllllll}
\hline \hline & \multicolumn{7}{c}{ Design \# } \\
\cline { 2 - 8 } Parameters & 63 & 88 & 124 & 143 & 158 & 270 & $410^{\mathrm{a}}$ \\
\hline$L_{\mathrm{m}}(\mathrm{mm})$ & 7.5 & 9.5 & 8 & 7 & 7 & 7.5 & 7 \\
$h(\%)$ & 0 & 10 & 5 & 0 & 5 & 10 & 0 \\
$\lambda_{\mathrm{d}}(\%)$ & 50 & 52.5 & 50 & 47.5 & 45 & 47.5 & 45 \\
$L_{\mathrm{yr}}(\mathrm{mm})$ & 7 & 7 & 7 & 8 & 8 & 8 & 8 \\
$W_{\mathrm{t}}(\mathrm{mm})$ & 11.3 & 11.9 & 11.3 & 10.8 & 10.2 & 10.8 & 10.2 \\
$N_{\mathrm{c}}$ & 24 & 24 & 24 & 28 & 22 & 22 & 28 \\
$D_{\mathrm{ct}}(\mathrm{mm})$ & 2.8 & 2.8 & 2.8 & 2.6 & 2.8 & 2.9 & 2.5 \\
$L_{\mathrm{t}}(\mathrm{mm})$ & 32.4 & 30.6 & 32.2 & 32.6 & 33.4 & 32.6 & 32.8 \\
$L_{\mathrm{a}}(\mathrm{mm})$ & 62.2 & 64.4 & 63 & 63.4 & 63.9 & 64.4 & 63.6 \\
$I(\mathrm{~A})$ & 28.0 & 28.4 & 28.2 & 23.4 & 28.5 & 29.4 & 22 \\
$P_{\mathrm{cu}}(\mathrm{W})$ & 56.8 & 56.1 & 57.2 & 56.3 & 55.2 & 55.8 & 54 \\
\hline \hline
\end{tabular}

${ }^{a}$ Design \#410 is selected because it is the one with the lowest current, and a powertrain motor with a lower current at rated load will improve the range of the electric vehicle.

\section{CONCLUSION}

An FE based design synthesis approach is demonstrated by developing a design program for SAT PMBLDC motor. Even though, the time taken for each design iteration with $\mathrm{FE}$ model is considerably more compared to analytical or lumped parameter models; accurate results can be achieved with significantly less program development time. The developed program is demonstrated by designing a traction motor for an electric two-wheeler.

\section{APPENDIX}

A. The variables defining the geometry of SAT PMBLDC motor

TABLE VI

GEOMETRICAL VARIABLES OF SAT PMBLDC MOTOR AND THEIR DEFINITION

\begin{tabular}{lll}
\hline \hline No. & Variable & Variable definition \\
\hline 1. & $D_{\mathrm{os}}$ & Outer diameter of stator \\
2. & $D_{\mathrm{is}}$ & Inner diameter of stator \\
3. & $L_{\mathrm{g}}$ & Axial length of airgap \\
4. & $W_{\mathrm{so}}$ & Width of slot opening \\
5. & $L_{\mathrm{sl}}$ & Depth of slot lip \\
6. & $L_{\mathrm{sm}}$ & Depth of slot mouth \\
7. & $L_{\mathrm{m}}$ & Depth of magnet \\
8. & $L_{\mathrm{yr}}$ & Depth of rotor yoke \\
9. & $W_{\mathrm{t}}$ & Width of stator tooth \\
10. & $L_{\mathrm{t}}$ & Axial length of stator tooth \\
11. & $L_{\mathrm{a}}$ & Axial length of motor \\
\hline \hline
\end{tabular}




\section{REFERENCES}

[1] T. J. E. Miller, Brushless permanent-magnet and reluctance motor drives. Oxford University Press, 1989.

[2] A. Cavagnino, M. Lazzari, F. Profumo, and A. Tenconi, "A comparison between the axial flux and the radial flux structures for PM synchronous motors," IEEE Transactions on Industry Applications, vol. 38, no. 6 , pp. 1517-1524, nov 2002.

[3] J. F. Gieras, R.-J. Wang, and M. J. Kamper, Axial Flux Permanent Magnet Brushless Machines. Dordrecht: Kluwer Academic Publishers, 2005.

[4] M. Aydin and T. Lipo, "Design and 3D electromagnetic field analysis of non-slotted and slotted TORUS type axial flux surface mounted permanent magnet disc machines," in IEMDC 2001. IEEE International Electric Machines and Drives Conference (Cat. No.01EX485). IEEE, 2001, pp. 645-651.

[5] T. F. Chan and L. L. Lai, "An Axial-Flux Permanent-Magnet Synchronous Generator for a Direct-Coupled Wind-Turbine System," IEEE Transactions on Energy Conversion, vol. 22, no. 1, pp. 86-94, mar 2007.

[6] N. Rostami, M. R. Feyzi, J. Pyrhonen, A. Parviainen, and V. Behjat, "Genetic Algorithm Approach for Improved Design of a Variable Speed Axial-Flux Permanent-Magnet Synchronous Generator," IEEE Transactions on Magnetics, vol. 48, no. 12, pp. 4860-4865, dec 2012.

[7] A. Mahmoudi, S. Kahourzade, N. A. Rahim, and W. P. Hew, "Design, Analysis, and Prototyping of an Axial-Flux Permanent Magnet Motor Based on Genetic Algorithm and Finite-Element Analysis," IEEE Transactions on Magnetics, vol. 49, no. 4, pp. 1479-1492, apr 2013.

[8] Y.-P. Yang, Y.-P. Luh, and C.-H. Cheung, "Design and Control of Axial-Flux Brushless DC Wheel Motors for Electric Vehicles-Part I: Multiobjective Optimal Design and Analysis," IEEE Transactions on Magnetics, vol. 40, no. 4, pp. 1873-1882, jul 2004.

[9] F. Chuang, "Optimization for Reduction of Torque Ripple in an Axial Flux Permanent Magnet Machine," IEEE Transactions on Magnetics, vol. 45, no. 3, pp. 1760-1763, mar 2009.
[10] T. Woolmer and M. McCulloch, "Analysis of the Yokeless And Segmented Armature Machine," in 2007 IEEE International Electric Machines \& Drives Conference, vol. 1. IEEE, may 2007, pp. 704-708.

[11] W. Fei, P. C. K. Luk, and K. Jinupun, "A new axial flux permanent magnet Segmented-Armature-Torus machine for in-wheel direct drive applications," in 2008 IEEE Power Electronics Specialists Conference. IEEE, jun 2008, pp. 2197-2202.

[12] F. Giulii Capponi, G. De Donato, and F. Caricchi, "Recent Advances in Axial-Flux Permanent-Magnet Machine Technology," IEEE Transactions on Industry Applications, vol. 48, no. 6, pp. 2190-2205, nov 2012.

[13] H. Vansompel, P. Sergeant, L. Dupre, and A. Van den Bossche, "Axial-Flux PM Machines With Variable Air Gap," IEEE Transactions on Industrial Electronics, vol. 61, no. 2, pp. 730-737, feb 2014.

[14] S. Kahourzade, A. Mahmoudi, H. W. Ping, and M. N. Uddin, "A Comprehensive Review of Axial-Flux Permanent-Magnet Machines," Canadian Journal of Electrical and Computer Engineering, vol. 37, no. 1, pp. 19-33, 2014.

[15] P. Campbell, "Principles of a permanent-magnet axial-field d.c. machine," pp. 1489-1494, dec 1974.

[16] M. Ehsani, K. Rahman, and H. Toliyat, "Propulsion system design of electric and hybrid vehicles," IEEE Transactions on Industrial Electronics, vol. 44, no. 1, pp. 19-27, 1997.

[17] J. Hendershot and T. Miller, Design of brushless permanent-magnet machines, 2010.

[18] T. J. Woolmer and M. McCulloch, "Axial flux permanent magnet machines: a new topology for high performance applications," in IET Hybrid Vehicle Conference 2006, vol. 2006. Coventry, UK: IEE, 2006, pp. 27-42.

[19] D. Ishak, Z. Zhu, and D. Howe, "Comparison of PM Brushless Motors, Having Either All Teeth or Alternate Teeth Wound," IEEE Transactions on Energy Conversion, vol. 21, no. 1, pp. 95-103, mar 2006. 